\title{
Probationary or second-class citizens? Postdoctoral experiences in the Swiss context
}

\author{
Nicky Le Feuvre ${ }^{1}$, Pierre Bataille ${ }^{2}$ and Marie Sautier ${ }^{1}$
}

Or. Ref.

Le Feuvre, N., Bataille, P., \& Sautier, M. (2020). Probationary or Second-Class Citizens? Postdoctoral Experiences in the Swiss Context. In S. Sümer (Ed.), Gendered Academic Citizenship (pp. 65-101). Springer International Publishing. https ://doi.org/10.1007/978-3-030-52600-9 3

\begin{abstract}
Irrespective of national and disciplinary specificities (Le Feuvre et al 2018), the conditions of entry to an academic career are generally recognized as being increasingly selective in the contemporary context. In the competition for a reduced number of stable or permanent academic positions, recently qualified $\mathrm{PhD}$ graduates who want to pursue an academic career face two main challenges. On the one hand, they have to accept a succession of fixed-term, often part-time and badly paid, precarious positions (generically designated as ?postdocs?), that have become a prerequisite for selection to more stable and permanent positions in the global academic labour market. On the second hand, access to these positions usually requires some form of geographical? usually transnational? mobility, which removes them from their existing social networks. In this chapter, we propose to analyse the effects of the combination of precarious employment positions and geographical displacement on the gendered citizenship experiences of postdocs working in a specific academic context. On the basis of qualitative (biographical interview) and quantitative (on-line web survey) data collected in the course of the GARCIA project (www.garciaproject.eu), we will examine the citizenship challenges faced by postdocs from across the globe who are working in the Swiss academic context.
\end{abstract}

\section{Introduction}

Despite national specificities, the academic profession is generally recognized as being increasingly selective and segmented (Le Feuvre et al., 2018). The intensified competition for stable academic positions is due to three parallel phenomena : an exponential increase of $\mathrm{PhDs}$ awarded by Higher Education and Research (HER) institutions in recent years, the continuing attractivity of an academic career to $\mathrm{PhD}$ graduates, and a limited number of permanent faculty positions to which prospective academics could be recruited (Jedliki \& Pudal, 2018).

These processes have led to an increase in the number and duration of fixed-term positions through which $\mathrm{PhDs}$ are expected to pass on their route to

1 University of Lausanne, NCCR LIVES, Switzerland, ${ }^{2}$ Université Grenoble-Alpes, LaRAC, Switzerland

Auteur correspondant:

Nicky Le Feuvre, University of Lausanne, Geopolis, Switzerland. Email: nicky.lefeuvre@unil.ch a stable academic career. Appearing under a diverse range of denominations and contractual arrangements, many of the fixed-term positions that exist within HER institutions are designated by the generic term 'postdoc'. All national contexts have witnessed an increase in the number of such positions, although the rate of expansion has varied by country and by disciplinary field (Murgia \& Poggio, 2018). For example, between 2000 and 2012, it has been estimated that there was a $150 \%$ increase in the number of postdocs in science in the United States of America, whilst the number of full-time faculty positions plateaued (Powell, 2015 : 144). As a consequence, the 'queue' for access to stable academic jobs has lengthened (Reskin \& Roos, 1990), competition has increased, and working conditions associated with such positions have been aligned with the general shift towards 'marketisation, managerialism and performance management' (O'Neill, $2014: 1$ ) within the HER sector across Europe and beyond.

Due to this 'postdoc bubble', an increasing share of scientific knowledge across the globe is produced by individuals who have no durable contractual 
relationship to a specific academic institution and who are subjected to a series of precarious employment contracts, potentially in different universities spread across the globe (Conesa Carpintero \& González Ramos, 2018). Thus, what it means to be a 'postdoc' has become increasingly blurred over time (Bataille \& Sautier, 2019). Such positions were traditionally seen as the first stage of an academic career, but they now lead to a wide range of occupational outcomes and offer varied forms of incorporation into the academic community. In some countries, temporary postdocs still represent a stepping-stone towards a stable academic career and full academic citizenship. In other contexts, they have become occupational outcomes in their own right, having displaced or replaced the permanent academic positions of the past, leading to what some authors have called 'permadoc' status (O'Keefe \& Courtois, 2019), whereby individuals remain in the HER sector for many years after their $\mathrm{PhD}$, without ever being offered a permanent or stable academic position.

In this chapter, we adopt the multi-level definition of academic citizenship outlined previously (Chapter 1 ), in order to explore the experiences of a particular group of postdocs working in a Swiss university, taken as an illustrative case-study. Although the increasingly precarious employment status of postdocs has started to attract some research attention (Murgia \& Poggio, 2018), little is known about the 'feelings, experiences, and narratives of being included and excluded, recognized and misrecognized, heard or ignored' (Roseneil et al., $2012: 5$ ) that members of this transient intellectual labour force develop towards the academic institutions through which they pass in the course of their 'precarious postdoc' (Jones \& Oakley, 2018) trajectories.

Using biographical interview and focus group data collected in the course of the GARCIA project, we adopt the notion of 'probationary citizenship', initially developed by migration scholars (Chauvin \& GarcésMascarenas, 2012), to provide new insights into the contradictory expectations placed on this particular group of early-career academics, and analyse their implications for the gendering of academic citizenship more generally The chapter is organised in four parts.

First, against the backdrop of the numerical expansion of the 'postdoc' category within academic labour markets, we present the theoretical framework of our analysis, which builds on the notion of 'probationary citizenship', initially developed to study the legalization process of undocumented migrants in different national settings. This conceptual framework enables us to explore the conditions under which postdocs are currently employed and to study the processes through which they are expected to demonstrate their 'deservingness' of full academic citizenship. Just like undocumented migrants, postdocs are faced with potentially contradictory expectations or 'divergent prescriptions' (Chauvin \& GarcésMascarenas, 2012). We suggest that they experience the postdoc period as a time when they are exposed to the alternative paths of definitive exclusion from the academic career path (non-citizenship), on the one hand, or of potential access to full academic citizenship status, on the other. However, depending on their gender, nationality, disciplinary background and family circumstances, the promise of full academic citizenship always comes with the risk of becoming trapped on the margins of the scientific community, in a durable 'limited' or 'second-class citizenship' status.

Secondly, we provide some statistical evidence of the extent of 'postdoc bubble' in the Swiss context and pinpoint some of the specificities of the academic labour market in Switzerland, as compared to other national contexts (Le Feuvre et al., 2014). We also present the data and research methods used in this study.

In third place, we present several aspects of the 'probationary citizenship' experiences of postdocs that emerged from our fieldwork (Bataille, 2016; Fassa et al., 2016; Le Feuvre, 2016). More precisely, we explore the divergent prescriptions postdocs face in relation to their employment and working conditions, their social protection, their scientific recognition, and their intimate and personal lives, and assess the consequences for these contradictory expectations on their professional aspirations and career outcomes.

In a fourth and final section, we summarise the implications of our findings for the study of gendered academic citizenship. We argue that, although the 'probationary citizenship' experiences of women are not radically different to those of their male counterparts, the outcomes of the postdoc period do tend to be distinctly gendered, particularly in the Swiss context.

\section{'Probationary citizenship' as a fra- mework for analysing the postdoc- toral experience}

One of the main aims of our paper is to analyse subjective citizenship experiences of the so-called 'postdoc bubble' in a particular institutional context. With this objective in mind, we suggest that academic citizenship always needs to be approached from a 
biographical or life-course perspective. The exclusion or inclusion processes at work within the academic community cannot be fully understood without sufficient consideration of the mechanisms through which aspirations and expectations are elaborated and consolidated over time, and in relation to other life domains. It is the dynamic and evolutive character of academic citizenship that inspired us to explore the analytical potential of concepts developed in the field of migration studies. Irrespective of the transnational mobility increasingly required of prospective academics (particularly those from non-English speaking countries), we believe that the 'precarious postdoc' (Jones \& Oakley, 2018) experiences of our respondents are not entirely unlike those of certain 'illegal' migrants, who already reside in the country to which they aspire to be formally admitted.

With the growth of undocumented immigration, the term 'informal citizenship' (Sassen, 2002 : 282) has been used to describe the reality of some migrants who, despite their illegal status, are able to access a series of 'citizenship rights' (e.g. economic resources, legal protection, housing, social services, education and public activism) in their country of settlement. The analytical insights drawn from this term have inspired other authors to reflect on the ambiguity of access to these rights for the legalization of illegal migrants. For example, in a number of countries, undocumented migrants are required to prove of their successful 'integration' into the host country in order to enhance their chances of legalization. At the same time, as illegal migrants, they are not formally entitled to the 'rights' that they are required to have acquired (through illegal or informal means), including a paid job, health insurance, a home, an education for their children, etc. Sébastian Chauvin \& Blanca Garcés-Mascarenas (2012) use the notion of 'probationary citizenship' to explore the 'divergent prescriptions' that illegal migrants face on their journey to full citizenship. In so doing, they identify the risk of 'subordinate incorporation' (Chauvin \& GarcésMascarenas, $2012: 8$ ) of undocumented migrants into specific nation-states; their physical presence is real, but their life-chances are limited by their precarious legal status. More precisely, these authors stress that undocumented migrants are increasingly required to demonstrate 'deservingness' of full citizenship, by conforming to the norms and by performing at least some of the tasks that are part and parcel of what it means to be a citizen, whilst living on the margins of the host community (ibid.).
The notions of 'divergent prescriptions', 'deservingness' and 'subordinate incorporation', struck a chord with our own reflections on the precarious postdoc predicament in the Swiss context. Historically, postdocs were clearly considered as 'subordinate' members of the academic community. They were expected to 'learn their trade' and to 'prove their worth' by working under the authority and patronage of a more senior academic (and often to his/her personal advantage), before progressing onto full membership of the academic community in their own right within a relatively short time-frame $(3-5$ years after the $\mathrm{PhD}$ defence). Of course, during this process, some postdocs were denied community membership, usually on the basis of their failure to reach various measures of 'academic excellence' (for a critical discussion of this notion, see Chapter 2 in this volume) within a predefined timescale. This 'up or out' career structure has traditionally been detrimental to women, and to mothers of young children in particular, in that it defined a limited time-frame in which individuals had to prove their worthiness of full membership of the academic community (Beaufaÿs \& Krais, 2005), or run the risk of definitive exclusion and relegation to 'non-citizenship'. The postdoc period has thus always been a time of 'probation', when aspiring academics were expected to demonstrate their 'deservingness' of full membership of the academic community through a variety of means.

However, the probationary citizenship experiences of the current generation of postdocs differ from those of their predecessors in three essential ways. First, the likelihood of a successful transition from probationary postdoc to full academic citizenship has significantly decreased over time (Enders \& Musselin, 2008, $132: 140$ ). Secondly, the duration of the probationary postdoc period has increased considerably, placing individuals in a prolonged period of uncertainty about the future direction of their professional and personal lives. And, finally, the conditions required to successfully transition to a permanent academic career have become more obscure, and potentially contradictory.

We argue that it is useful to see the postdoc period as a time of 'weird limbo' (as one of our interviewees put it), characterised by structural uncertainty and embodied anxiety (Sigl, 2012). The completion of a $\mathrm{PhD}$ requires successful candidates to perform most of the tasks that will eventually serve as selection criteria for full membership of the academic community. Most postdocs have confirmed their desire for recognition as independent scientists, by applying for positions that are presumed to be 'stepping stones' towards an academic career. This progression is predicated on the 
accumulation of relevant experience in the core tasks of the profession and on the external evaluation and validation of the 'performance' levels of those who aspire to remain within the academic community, on a permanent basis. And yet, satisfactory completion of these core professional tasks does not provide guaranteed access to full academic citizenship.

In the Swiss context, the transient status of a large number of internationally selected postdocs offers a variety of potential outcomes, including full academic citizenship (via access to a tenure-track or tenured academic professorship), limited or secondclass citizenship, in the form of relatively stable positions that involve a combination of teaching, research and administrative tasks, but that are not designed to enable subsequent progression to a tenured professorship, and thwarted or non-citizenship, in the form of voluntary or involuntary exit from the academic career structure, although not necessarily total exclusion from the academic labour market, since these postdocs may continue to carry out fixed-term, part-time teaching, research or administrative duties within HER institutions for a number of years. This latter option corresponds to a form of 'subordinate inclusion' in the academic labour market, which makes it difficult for individuals to envisage an alternative (non-academic) career, but which provides few of the rewards or recognition associated with academic citizenship.

We would argue that the moral contract that historically linked academic institutions, senior academic mentors and postdocs around a limited 'probationary' phase is currently under considerable strain. The historical status of postdocs was predicated on their progressive integration into the academic community within a predictable time-frame. But, much like undocumented migrants in the Global North, todays' generation of postdocs are under increasing pressure to demonstrate their deservedness of the whole range of rights associated with full academic citizenship, at a time when expectations about what they actually need to achieve are increasingly unclear and/or unrealistic (Warren, 2019). Thus, as competition for the relatively few stable academic jobs increases, the rising number of 'permadocs' (O'Keefe \& Courtois, 2016) poses a potential threat to the cohesion of the academic community as a whole. The stunted rights, rewards, and recognition offered to individuals during the 'probationary' postdoc phase can no longer be bolstered by the promise of future membership of the academic community, and, as we will show later, this shift may lead to new forms of gender segregation within $\mathrm{HE}$ and research institutions.

\section{The Swiss 'postdoc bubble' in comparative perspective}

The Swiss academic market is characterized by relatively low levels of employment security and by high levels of international recruitment (Afonso, 2016). In addition, Swiss postdocs are usually placed under the administrative and moral authority of a senior academic, but are expected to demonstrate their intellectual autonomy and 'leadership potential' in order to progress onto a permanent professorial appointment.

\section{Postdoc insecurity : an unpredictable succession of fixed-term contracts}

In Switzerland, universities are funded and regulated at the cantonal level. They are free to define their own academic career paths, as well as the duration, denomination, and conditions of recruitment to different temporary or permanent positions (see Afonso, 2016). Over 15 different denominations are used to designate academic jobs in Switzerland, as compared to the standard international trilogy of 'PhD, postdoc, tenure-track assistant professorship'. There is thus considerable variation in the type of positions available or used in the different Faculties of each HE institution. A small minority of HE \& research institutions offer permanent positions that are equivalent to Senior Lecturers or Readers in other national contexts, while others only offer stable jobs at Associate and Full Professor levels. However, the Swiss academic career model remains similar across institutions as far as the duration of the 'probationary' postdoc period is concerned. In a country where the majority of $\mathrm{PhDs}$ are awarded to people in their mid30s (Dubach et al. 2017 : 53), access to a tenured professorship before the age of 40 is rare, especially in the Humanities and Social sciences, which account for a large share of female PhDs (Fassa and Kradolfer, 2013). The 'postdoc' period is therefore likely to last for a minimum of 7-10 years, sometimes more.

Given the prolonged length of the pre-tenure period in the Swiss context, it is common for $\mathrm{PhD}$ holders to benefit from more than one source of postdoc funding, either simultaneously (combining several parttime positions, potentially in different institutions) or in succession (running the risk of periods without income between assignments).

A first type of postdoc positions are funded directly by the university and form an integral part of their internal labour markets. These positions (e.g. Premier Assistant.e or Maître Assistant.e) usually involve a 
combination of research and of teaching (or assisting teaching) duties.

A second set of postdoc positions, mostly researchbased, are funded by the Swiss national research council (SNSF), or other external funding bodies. These funds are usually secured on a competitive basis by tenured academics. Professors are not allowed to 'buy themselves out' of their statutory teaching and administrative duties (as is the case in other national contexts). As 'principal investigators' (PI) they recruit $\mathrm{PhD}$ candidates and post-docs to carry out the proposed research programme.

These postdoc positions may be full- or part-time. The former category is renewable on an annual basis, for a maximum duration of five or six years, while the later usually last for 1 to 3 years.

A third category of positions is available for postdocs who access research funding directly. At the SNSF, for example, "career funding" opportunities require them to undertake extended periods of international mobility (12 - 36 months), to work under the supervision of a senior (tenured) academic in a (preferably prestigious) foreign university. In this case, the funding presumes full-time employment and may include a 6 month 'return phase' to a Swiss university and a top-up grant to cover the expenses of an accompanying spouse and children.

In addition to these three types of formal postdoc positions, there are also some 'hidden' or 'clandestine' postdocs in Swiss $\mathrm{HE}$ and research institutions. These are people who are recruited to what are nominally administrative or technical positions, but which actually include a variety of research (support) or teaching (supervisory) duties. The development of these clandestine postdoc positions is difficult to track with precision, but they would appear to be an unintended consequence of measures taken by the Swiss authorities to reduce the 'precarity' of early academic careers. Thus, for example, the SNSF considers that the post-doc status should be limited in duration and provides a sliding scale for postdoc salaries, including recognition of previous work experience, that reaches a ceiling at $\mathrm{PhD}+5$ years. Once this duration has been exceeded, the expectation is that the postdocs who have not (yet) secured a professorship will 'exit' the academic labour market. Some Swiss universities also limit the number of years that can be spent in any combination of post-doc contracts in the same institution, while others allow PhDs to occupy a succession of postdoc jobs with no limit to their total duration. In many disciplinary fields, the 5-year cut off point is well below the academic age at which most professors are actually recruited. Whilst not recognised as being part of the academic career track, administrative or technical positions may be used to shelter some junior colleagues from the requirement to leave an institution after the authorized duration of the formal postdoc phase, in order to further bolster their track record (publications and grants) with a view to eventually applying for a permanent academic position. Alternatively, these 'pseudo-' postdoc positions may be offered as an alternative to an academic career, and thus signify the definitive shift from a 'probationary' to a more permanent type of 'limited' or 'second class' academic citizenship.

Due to the variety of denominations of postdoc positions in Switzerland, it is extremely difficult to track their development over time. Between 2000 and 2012, an official study of the staffing levels of Swiss HERIs distinguished between five occupational categories, according to academic rank, qualification (pre- or post-PhD) and employment conditions (tenured or fixed-term) $)^{1}$ (Figure 1).

Largely due to rising student numbers, employment increased in all five categories over the period 20002012 , although rates of growth varied significantly by occupational status. Despite an increase in absolute numbers $(+45 \%)$, the relative share of tenured or tenure-track professorial positions remains extremely low, confirming EU estimates that show that professors represent only $12 \%$ of male academic staff and $4.7 \%$ of female academic staff in Swiss universities (SHE Figures $2016: 132)$. In contrast, the increase in the Postdoc category (fixed-term teaching and/or research positions for $\mathrm{PhD}$ holders) has been expanding considerably faster $(+104 \%)$, in line with that of the more heterogeneous category of 'Other teaching staff' $(+90 \%)$, which, along with the 'Admin \& Technical staff' category, may include a number of 'clandestine postdocs'. The increased gap between the number of postdocs on the one hand, and the number of stable professorial positions (Prof.) on the other hand suggests that the Swiss 'survivor' career model identified by Jürgen Enders and Christine Musselin (2008) is becoming even more selective over time.

\section{Postdoc mobility : inbound and outbound circula- tions on an international scale}

The Swiss academic market is not only characterized by extended periods of employment insecurity, but also by extremely high levels of international mobility. As one of the most internationalised academic labour markets in the world, Swiss universities register high 


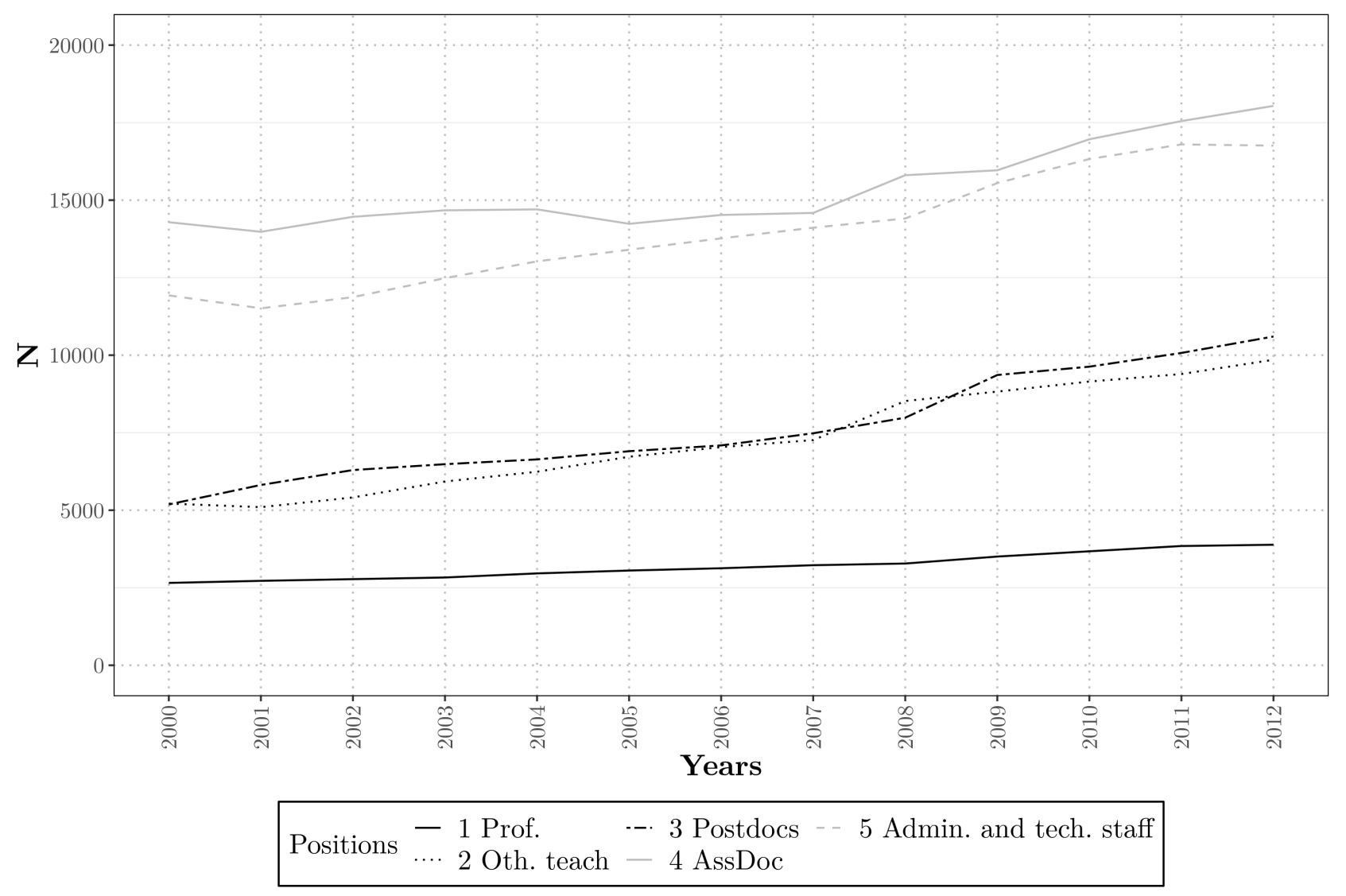

Figure 1: Composition of Academic Staff in Swiss HE \& Research Institutions (2000-2012) Source : OFS, 2017.

rates of both inbound and outbound mobility (see Table 1).

Less than $40 \%$ of $\mathrm{PhD}$ candidates affiliated to a Swiss higher education institution are Swiss citizens or Swiss-educated foreigners, while the remaining twothirds come from abroad. Women represent a slightly larger share of foreign than Swiss PhD candidates, but the sex and mobility ratios also vary by disciplinary field. Thus, foreigners account for about $70 \%$ of $\mathrm{PhD}$ candidates in economics and the natural sciences, but only $47 \%$ of those in the social sciences and $28 \%$ in Law.

Foreigners also make up a large share of the Swiss academic workforce. In 2017, only $34 \%$ of 'scientific collaborators' (PhDs and Postdocs) were Swiss citizens, and this was also the case for $39 \%$ of the tenured or tenure-track professors, as compared to $44 \%$ in 2008 (OFS, 2017), although some of these foreigners may have received their $\mathrm{PhD}$ from a Swiss university (Nokkala et al., 2020).

All early-career scientists who received their $\mathrm{PhD}$ in Switzerland are encouraged to spend at least 12 months in a foreign research institution (Sautier, 2017), irrespective of their nationality. Being internationally mobile has long been a requirement for access to most stable academic positions, but it is also expected for many of the fixed-term positions mentioned previously.

Early-career researchers are thus faced with the challenge of moving abroad and of re-locating frequently (with all this entails for their personal and family lives) whilst 'surviving' a succession of fixed-term, often part-time, teaching and/or research positions, characterised by extreme uncertainty.

Source : Dubach et al., 2017 : 51, own calculations.

Postdoc subordination : issues of intellectual autonomy and leadership potential

Whatever their precise status, postdocs exemplify the ambiguities of the Swiss academic career model, where membership and belonging to the academic community are partly detached from formal employment conditions and monetary rewards, and where the research output and reputation of tenured 
TABLE 1: Foreigners as share of PhD candidates at Swiss Universities (2015)

\begin{tabular}{llllll}
\hline & PhD candidates & \multicolumn{3}{c}{ Women } \\
\hline Disciplinary Field & Total & $\mathrm{Sw}^{2}(\%)$ & Tot. $(\%)$ & $\mathrm{Sw}(\%)$ & Foreign-ed. cand. (\%) \\
Social sciences & 976 & 53.0 & 56.5 & 57.6 & 55.3 \\
Economics & 310 & 30.0 & 36.5 & 31.2 & 38.8 \\
Law & 328 & 71.6 & 47.9 & 45.5 & 54.0 \\
Natural sciences & 1635 & 28.9 & 42.2 & 31.5 & 46.5 \\
Technical Studies & 776 & 24.6 & 28.7 & 22.5 & 30.7 \\
Total & 4053 & 37.6 & 43.3 & 41.7 & 44.3 \\
\hline
\end{tabular}

professors is largely dependent on their ability to attract (and retain) productive and committed postdoc 'research collaborators' to whom they can offer only fixed-term employment opportunities in return.

Quite logically, almost all of the postdoc positions described above imply a degree of formal subordination to an individual tenured professor (or PI), who is often referred to as the 'boss' and who effectively selects postdocs - often single-handed - from the (usually large) pool of applicants, and determines to a large extent their employment and working conditions, within the HR guidelines laid down by the cantonal authorities. In the Swiss context, postdocs are thus heavily dependent on the mentorship and patronage of their successive supervisors and PIs for access to a whole range of resources that will ultimately enable them to 'survive' for the lengthy time required to qualify for a (semi-) permanent academic position (generally associated with the right for them to supervise PhDs and to recruit 'their' own postdocs in turn).

In practice, several factors hinder the smooth transition from 'probationary' to full academic citizenship for the majority of the postdocs working in Switzerland.

Firstly, as mentioned previously, the formal postdoc period is not actually long enough to take the PhDs up to the 'academic age' and/or career stage where they can objectively hope to be recruited to a professorship (as we have seen, usually at $\mathrm{PhD}+7$ years, sometimes much more). The idea that the tenure process should take place earlier appears to be wishful thinking on the part of the authorities, since there is widespread evidence that the explicit or tacit requirements for access to a professorship cannot objectively be met within the designated time-frame, at least not while maintaining an acceptable level of mental and physical health and a semblance of social or family life outside of work (Fassa \& Kradolfer, 2013). This is particularly true in disciplines where there are almost no tenuretrack (assistant) professorships, and where the only solution for post-docs who have already been working in a particular institution for up to five years - and who want to stay there - is the creation of a professorship in their own department, in an area sufficiently close to their own expertise, and to which they could apply. This 'open' application process brings them into competition with (often more established) members of the international academic community, attracted by the relatively comfortable employment conditions offered by Swiss universities (Afonso, 2016), and who are more easily taken seriously as 'independent scholars' than the 'local' postdocs.

Secondly, there is the thorny question of the alternative career opportunities that might be available to the highly qualified men and women who have been trained and specialised in nothing but 'research (and some teaching) excellence' for the past 10 years. Previous studies have shown that opportunities for non-academic careers in Switzerland are highest in those disciplinary fields where the share of female PhDs is lowest (Studer, 2012). In other words, the decision to undertake doctoral studies is not unrelated to the gender segregation of the Swiss education system and labour market. Through a longitudinal study of Swiss graduate career paths, Studer (2012) found that female MA graduates in the Humanities and Social sciences are more likely to continue their studies (as funded $\mathrm{PhDs}$ ) than their male counterparts, precisely because they perceive the university environment to be less discriminatory than most alternative employment sectors. Our interviews confirm that non-academic employment opportunities are also scarce for postdocs in the most feminized disciplinary fields ( $\mathrm{SSH}$, but also the life-sciences), leading to a willingness of some (female) postdocs to accept unpredictable, flexible working conditions in academic institutions, even without any prospect of tenure. 
Finally, there are the interests of the institutions and the senior academics themselves, who are generally eager to continue collaborating with the postdocs they have selected according to precise criteria, and who have already become at least surrogate members of the academic community. Should these worthy candidates prove unsuccessful in their attempts to achieve full academic citizenship, the temptation to continue employing them, even with a definitively 'subordinate' status, results from a combination of at least two factors, first, the self-interest of the PIs (who trust them to produce sound research, to get their joint work published in the right journals and to help with future grant applications). Second, a sense of moral obligation to at least some of their research collaborators, since it would be unethical not to reemploy someone who has been loyal and productive.

Due to the 'up or out' logic that underpins the Swiss academic career structure, there are actually few permanently subordinate postdoc positions in the country. In the institution where our field-work was carried out, recruitment to the few teaching-only, parttime, fixed-term positions is formally limited to those candidates who could prove that they had a 'principal employer' elsewhere (for income tax purposes). Thus, in Switzerland, postdoc precarity is less likely to take the form of part-time 'crumb jobs' (although these do exist) and more likely to result from the nonrenewable character of employment contracts that require postdocs to fulfil almost all the criteria of professorial recruitments, whilst rarely enabling them to secure the rights and rewards associated with full academic citizenship.

The 'probationary' postdoc period thus requires individuals to demonstrate their 'total commitment' to the scientific endeavour, to meet ever more demanding 'performance' objectives (publications, grants, awards, etc.), and to accept their subordination to a tenured individual on whom they depend both for immediate survival (a job), for their well-being (work-life balance) and for their academic future (the patronage required to access the next step along the highly competitive academic career track, in Switzerland or abroad). At the same time, the transition out of this probationary phase requires postdocs to demonstrate 'leadership potential' and intellectual autonomy.

With such contradictory expectations hanging over them, it is hardly surprising that the citizenship experiences of Swiss postdocs are fraught with material and emotional tensions, many of which have gendered aspects and implications.

\section{Research Data \& Methods}

The empirical data analysed here were collected during the GARCIA research project. Involving partners from Austria, Belgium, Italy, Iceland, The Netherlands, Slovenia and Switzerland and using a mixed-methods design, it aimed at studying the early stages of the academic career path (between $\mathrm{PhD}$ defence and a permanent academic or non-academic position, i.e. the moment when women tend to 'leak' from the academic career pipeline) (Dubois et al., 2018). In each country, we interviewed the same number of men (20) and women (20) who had been hired as postdocs in the STEM or SHS fields at a particular university, between 2010 and 2013. Our aim was to cover as many potential employment outcomes as possible, including subsequent postdoc or fixed-term contracts, tenure-track or tenured academic positions, non-academic employment (including unemployment and non-employment).

In addition, an on-line survey was fielded to all the former STEM and SHS postdocs of the partner institutions $(\mathrm{n}=339)$, in order to collect data about their postdoctoral experience in the different countries, their career path since leaving the institution, and their aspirations for the future. We also collected administrative and internal survey data from each partner institution and carried out focus groups with senior academics involved in recruiting postdocs and permanent academic staff.

Although we ensured a gender balance of interviewees from each of the disciplinary fields, we did not control for nationality, and our study population reflects the large number of foreign postdocs working in Switzerland (22 interviewees out of 40 were foreign citizens), particularly in the STEM fields (17 out of 20).

\section{The 'probationary citizenship' ex- periences of postdocs in the Swiss context}

In this section, we use interview and focus group data from the GARCIA research to explore different aspects of the 'probationary citizenship' experiences of our postdoc interviewees in the Swiss context. We pay special attention to the 'divergent expectations' faced by these surrogate members of the academic community, who are expected to demonstrate all the qualities of the academic citizen, whilst working on fixed-term contracts, under the authority of a senior academic, struggling to build up their personal 
reputation and research profile. This somewhat contradictory expectation creates extreme uncertainty for the postdocs as to their ability to maintain sufficient proof of their 'deservingness' of full membership of the academic community whilst juggling with a succession of geographically dispersed, non-renewable, precarious employment contracts and ensuring the continued patronage of senior academic gatekeepers.

As we have seen, Swiss postdocs are required to demonstrate their full commitment to the academic work ethic, with hope of only indirect recognition in return. It was usually made clear to our interviewees from the outset that there would be no long-term future for them in the institution to which they were about to commit several years of their lives, frequently having moved long distances, at personal expense, to take up their jobs. Adhesion to the academic ethos is expressed through unlimited availability for work, a competitive 'pace' of productivity, a contribution to the more mundane aspects of 'academic housework' (Heijstra et al, 2017) and submission to the research priorities of the PI, on the understanding that this investment can't be rewarded in the form of a permanent position in that institution. The justification for this intensive, sometimes gruelling schedule, is based on the idea that by demonstrating their willingness to adopt the 'all invasive' commitment of the contemporary academic, the postdocs will ultimately be recognized as deserving full membership of the academic community in general, and thus increase their chances of being recruited elsewhere.

This disjuncture between the institutional setting where the postdocs are required to demonstrate deservingness and the unspecified location where they could (potentially) reap reward for this lengthy commitment to a 'greedy institution' (Coser, 1974; del Río Carral \& Fusulier, 2013), is a source of much dissatisfaction and 'embodied anxiety' (Sigl, 2012) on the part of the postdocs we interviewed. Their accounts reveal at least three types of risk related to their 'probationary' status. One relates to material working conditions and to the difficulty postdocs face in accessing employment rights, including basic social protection (Murgia \& Poggio 2018). Another relates to the recognition of their scientific autonomy, leadership potential and overall 'excellence' (Fassa et al., 2019). A third relates to the subordination of their private lives to the unpredictable calendar and geographical dispersion of the precarious postdoc path. For analytical clarity, we will provide empirical evidence of each of these risks in separate sub-sections, whilst recognising that they usually co-exist in the accounts of the postdocs we interviewed.
The risk of precarious employment and limited social protection : 'you're basically just a temp'...

Our interviews abound with accounts of postdocs facing limited employment and social protection rights and being made to feel like dispensable, temporary workers, despite years of educational investment and qualifications. The highly competitive, international market for access to Swiss universities, along with the transient nature of the postdoc contracts, and the importance of patronage from senior academics combine to limit the ability and willingness of postdocs to defend their basic employment rights with any vigour. The most frequently cited abuses of their 'probationary' status concern the expectation for them to work extremely long hours, irrespective of their formally part-time contracts, and the requirement to accept an arbitrary allocation of workload and job content.

For example, Helena ${ }^{3}$, a Colombian postdoc who completed her $\mathrm{PhD}$ in Spain, before applying for a twoyear postdoc in Switzerland, is currently employed on a non-tenure-track assistant professorship, with a fixedterm contract at the same university. She is employed (and paid) part-time (75\%), while actually working "a lot more". Likewise, Julio - who is Spanish - completed his $\mathrm{PhD}$ in the UK, before taking up a postdoc position in Switzerland. Julio was highly motivated by the prospect of doing a $\mathrm{PhD}$ in order to start an academic career. After 18 months working on an interesting research project, he was about to take up a job in a large Swiss industrial firm, having abandoned any hope of an academic career :

"I didn't get the most motivating of situations to start with. For example, my contract [...] was part-time, $80 \%$, I thought : 'Oh great, I'll have Fridays off', until I actually arrived in the lab and they told me : 'No, you're expected to work at least full-time" [...] And, there's a high turnover rate. During the last year, three or four $\mathrm{PhD}$ students dropped out, right in the middle of their PhD. Really? Yes, because they couldn't stand the situation anymore, the pressure. I even heard the PI come out with a very nice sentence, he said : 'having lunch is for losers and for weak people!' laughs. That's the general atmosphere in the department"

Beside the objective lack of academic career prospects in the life-sciences, one of the reasons Julio finally decided to quit the academic career track was related to the employment conditions associated with 
the SNSF postdoc mobility scheme. Julio realised that the competitive funding would come in the form of a grant, rather than a salary, offering him no pension cover, no sick pay or, more importantly in his eyes, no right to unemployment benefit at the end of his 3-year, non-renewable, grant-period, to be spent abroad.

Another recurrent example of postdocs feeling as if they are being treated like 'temps' refers to the vague and unspecified nature of their job content, particularly as far as teaching duties are concerned. Not only are candidates poorly informed about the precise content of their jobs when they accept a postdoc position in our case-study university, they also have the impression that duties are allocated on an arbitrary basis, often at short notice, leading to unpredictable schedules and unstable workloads. Thus, postdocs who formally have the same job titles, employment contacts and salary scale end up assuming very unequal shares of 'academic housework' (Heijstra et al, 2017), in the form of tasks that bring little visibility or recognition, but that are necessary to the smooth running of all the rest. This leads to feelings of injustice and discrimination that can rarely be expressed openly, notably because work allocation is the role of the PI, on whom all the postdocs depend for future patronage.

Although male and female postdocs recount similar experiences of precarious employment and limited social protection, some issues do appear to be particularly discriminatory to women. Our interviews abound with tales of maternity leave being seen as a watershed on the academic career path of female postdocs, notably because a sign of anything less than total commitment to the research project automatically reduces their perceived 'deservingness' of full academic citizenship. However, at least in the Swiss context, maternity leave is seen as problematic not only because it risks reducing the scientific productivity of the postdoc, thus compromising her ability to compete on an equal footing with 'unhampered' candidates for tenured positions (Ward \& Wolf-Wendel, 2004; Wolfinger et al., 2008). There are actually a number of formal measures adopted (although still unevenly implemented) in Swiss universities, that enable female candidates to deduct any period of maternity leave, or any subsequent period of part-time employment, from their 'academic age', in order for their 'productivity' to be assessed only on the basis of their actual employment history. Rather, maternity leave is framed as problematic for the majority of our respondents essentially because it compromises the timely completion of the research project for which they were initially recruited. Since most Swiss universities have no policies for replacing women during their maternity leave (which lasts a statutory four months, with a possible one-month extension for breast-feeding) ${ }^{4}$, the risk of hiring a pregnant woman, or one who might decide to have a child during her (potentially lengthy) postdoc period, is seen to fall essentially on the PI, who will suffer most from the inability of the new mother to carry out the research according to plan. Some senior academics put considerable pressure on female postdocs to avoid pregnancy altogether, or to continue working (informally) during their maternity leave, as proof of their 'deservingness' support on the route to full academic citizenship.

This moral pressure, and the negative consequences of failing to succumb to it, transpire from the account of Floriane, a French woman who was recruited to work on a three-year SNSF-funded project in the Faculty of Biology \& Medicine. Floriane had a $1^{\text {st }}$ child during the last year of her PhD (in France), and moved with her husband and daughter to live near the Swiss boarder to take up her postdoc position. Although she initially thought that this 'sounded like the ideal job', relationships with her supervisor soured after she announced that she was pregnant again. She described her boss as 'a really nice guy', despite the fact that he made her feel that this was 'really, really not a good time to be pregnant [...] it really pissed him off'. Health problems during pregnancy, followed by the maternity leave itself, slowed down the data collection, and therefore reduced the research outputs.

"He imagined that I would work during my maternity leave. The worst thing is that I wasn't against the idea. I twice tried to do that, but it didn't work, it was impossible. I was just too tired."

Having compromised her 'deservingness' of continued support from her supervisor, and facing exhaustion from her attempts to compensate for her absence during the $2^{\text {nd }}$ year of the project, Floriane finally decided to abandon any idea of pursuing an academic career. At the time of interview, she was preparing to become a secondary school teacher.

\section{The risk of never becoming an independent scholar in your own right}

A second 'divergent expectation' mentioned by the interviewees relates to the issue of scientific autonomy and 'leadership potential', two clearly recognised criteria for recruitment to professorial positions in the Swiss academy. As we have seen, the primary role of a postdoc is to carry out a research programme that has been designed by their PI. This may involve data 
collection according to a predefined research protocol and/or the analysis (and publication) of data that has been collected prior to their joining the team. Tenured professors are actively encouraged to compete for external research grants, notably from the SNSF, and the number of (successful and unsuccessful) grant applications is used as a performance indicator in the professorial evaluation procedures. This funding generally comes in the form of salaries to recruit $\mathrm{PhD}$ students and postdocs, who are chosen (often with few internal constraints on selection criteria or procedures, see Fassa et al., 2016) by the PI, to whom they are expected to show appropriate signs of deference and subordination. The duty of a Swiss postdoc is first and foremost to ensure that the PI's research project is run effectively and timely, according to the agenda defined before they were recruited. This includes ensuring that research results are published in the appropriate form for the PI to bolster his/her research portfolio, and to thus continue receiving competitive research funding.

As with the pressure for unlimited availability, the scientific subordination required of Swiss postdocs is a double-edged sword. With the increase in multi-authored publications (Fire \& Guestrin, 2019), postdocs are likely to benefit indirectly from any scientific output from the projects they work on; since they can expect to figure among the co-authors of just about every piece of research that gets into print. Having a 'productive' PI is thus a definite bonus, because it increases the chances of constructing a solid research portfolio, one of the main criteria for recruitment to permanent academic positions. At the same time, becoming part of an internationally renowned research team can also lead to a lack of recognition of the postdoc as an independent and autonomous researcher in his or her own right.

One example of this lack of scientific autonomy is provided by Stephany, a 30-year-old US citizen who had arrived in Lausanne with her French husband three years previously. Having done their PhDs in the US, the couple chose Switzerland because the husband wanted to live in a French-speaking environment (a challenge for Stephany), and because there were plenty of postdoc job opportunities that matched their respective research profiles. They both ended up on postdoc contracts in different departments in our casestudy university. Stephany spontaneously mentioned the importance of relationships with senior academics as a key to her future academic career. She described her former $\mathrm{PhD}$ supervisor as unsupportive, favouring one of the male postdocs in the team. Although she has witnessed some professors acting as 'strong allies to their people', her own experience has been largely negative to date. As a post-doc, she is working under the joint supervision of two professors and generally feels that 'they really don't care' about her future as an academic. This lack of concern is clear to her in the absence of feedback about her work, the absence of collaboration, and a general feeling of indifference towards her as a person. She also describes the difficulties she faces in being taken seriously as an academic in her own right :

"I found a conference that I really wanted to go to, I wrote to my bosses, and I asked if I could go to this conference. One of them never wrote back (pause), the other one wrote back saying: 'Oh well, you know, I'm going to be going to that conference and so will your other boss. I will present your work, so you don't need to go' [...]. It's basically saying : 'I think your work is interesting, but, I'm not going let you get the... sort of... credit for it. [...] It was a sort of turning point for me in my feelings towards my bosses and then in my feelings towards a future career in research : 'If they're not even supporting me, then who will ?' No-one's going to do so."

Showing a clear understanding of the power relations involved in decisions about who is in a position to 'take the credit' for her work (Walsh, 2019), Stephany provides the following explanation of this unpleasant but not isolated experience :

"My boss is a relatively young professor, he's just got tenure, and... so he's in a position where he's trying to lift himself further up, even further than we are also trying to lift ourselves up. And so, I think he's, yeah, he's taking advantage of his power in that situation, in my opinion. He has done this with other people as well."

At the time of the interview, Stephany was seriously considering an alternative to an increasingly elusive academic career. However frustrating on a personal level this experience of academic subordination may be, it reflects the ambivalent 'probationary' status of postdocs in the Swiss context, which also creates a potential threat to their mental and physical integrity. As Stephany explains in the following excerpt, the lack of scientific autonomy of postdocs is institutionalized through their subordination to a senior academic and also through the notion that the postdoc is actually a period of continuing education and professional training : 
"One strange thing is that we are often hired on 80 or 90 percent contracts and this is never explained laugh. I've heard a variety of explanations, one of them was that we are still [...] being trained. But, no one is training us and there is no... I mean no one is invested in our future careers [...]. This is just an excuse they use to pay us less and to give us temporary contracts. And they don't do anything to give back".

However, as revealed in our focus groups with senior academics who had recently recruited postdocs or more senior colleagues (Herschberg et al., 2016), one of the first criteria for postdoc recruitment is to find someone 'more or less anywhere in the world' who is already competent in the field covered by the position, who needs only minimal supervision and who is able to undertake all of the tasks related to the successful completion of the project without any further training. The 'ideal postdoc' candidate is thus supposed to share all the characteristics of the ideal professorial candidate, with one major exception : the postdoc should contribute to the research objectives defined by the PI (whilst potentially reaping indirect, personal benefits from his or (more rarely) her aura), whereas the potentially successful professorial candidate is expected to have demonstrated the ability to define and complete an independent research program, and to manage a research 'team'.

This tension between scientific subordination and academic autonomy is exacerbated by the pressure increasingly placed on postdocs to contribute to the reputation of their host PI / research centre / university, by making their personal research output visible (and, therefore, 'accountable' in the various metrics of institutional performance), even in the explicit absence of any formal and durable employment contract covering the 'production cost' of this output (see Walsh, 2019).

The Swiss academic authorities are fully aware of the 'postdoc paradox' presented here. The SNSF has recently adopted a series of measures aimed at reducing the size of the 'postdoc bubble' and at giving earlycareer stage researchers the opportunity to develop their personal research agenda and leadership skills. These measures include placing a limit on the number of research grants ${ }^{5}$ that any senior (tenured) academic can receive at one time. Simultaneously, the SNSF has also made it possible for some limited categories of untenured academics ${ }^{6}$ to receive research grants in their own right. The idea of limiting the number of research projects tenured professors could manage at any point in time came in for stiff criticism, and has manifestly not been implemented in most SNSF funding bodies.

In addition, the 'career support' programme of the SNSF provides funding for a limited number of professorial fellowships, which do pay the salary of the postdocs themselves (and their 'team' of $\mathrm{PhDs}$ and/or postdocs), who become associate members of a chosen Faculty, for the duration of the Fellowship (potentially $4-6$ years), with no additional cost to the host institution. The influence of these career support measure on the size of the Swiss 'postdoc bubble' is debatable, since they basically involve a reallocation of resources. Tenured professors have fewer opportunities to recruit research collaborators on a fixed-term basis, whilst untenured junior academics are now able to employ temporary postdocs in their own right.

\section{The risk of missing out on intimate relationships and emotional stability}

The third contradictory requirement during the 'probationary' stage of the academic career is the subordination of emotional ties and intimate lives to the spatial - usually transnational - mobility that is a condition for access to successive postdoc positions. Predicated on the existence of an 'unencumbered global citizen', access to these jobs thus varies according to the nationality and marital status of the PhDs. The geographical mobility required of early career scientists tends to reinforce existing inequalities in economic resources and settlement rights (Sautier, 2017; Bataille and Sautier 2019). For example, the Swiss migration regime imposes annual quotas on the number of non-European citizens that can be admitted into the country at any one time and also requires them to leave the country immediately after the end of their employment contract, ${ }^{7}$ a constraint that is not imposed on postdocs from the EU (Seminario \& Le Feuvre, 2017). Likewise, 'family reunification' measures are much harder for homosexual couples to access and are reserved for Swiss nationals, or for those foreigners with a permanent Swiss resident permit.

The 'intimate citizenship' experiences (Roseneil et $a l ., 2012$ ) of postdocs are influenced by the contradictory expectations about intimate living arrangements that coexist under the Swiss 'probationary citizenship' regime. On the one hand, postdocs are expected to be 'unencumbered' by any care duties of their own, but they are also presumed to be able to call upon, if required, the emotional and practical support of their loved-ones on a daily basis. It is the combination of these two - usually implicit - expectations that enables 
PIs to impose 'elastic' working hours and unpredictable schedules on their male and female postdocs alike.

Postdocs are frequently caught up in moral dilemmas about the degree to which they should involve their loved ones in this uncertain period of their lives, particularly if this implies 'sacrifices' on their part. Given that the transitory nature and relatively lengthy duration of Swiss postdoc positions, our interviewees recount the complexity of deciding whether or not it is 'worthwhile' or 'feasible' moving with partners (and sometimes children) to a country that is rarely considered as their final destination on the road to full academic citizenship. There is also the prohibitive cost of securing accommodation and moving personal belongings to one of the most expensive countries in Europe, which often leads postdocs to adopt 'retarded student' living arrangements well into their late-30s or early 40 s.

The decision to move alone or with loved ones is further complicated by three aspects of the Swiss academic context that have direct implications for the gendering of academic citizenship : a high level of homogamy, especially for female postdocs, who are more frequently involved in partnerships with other aspiring (male or female) academics than their male counterparts (Le Feuvre, 2009) ; increasing 'dual career' expectations on the part of highly qualified couples in the European context; and a very conservative Swiss gender regime (Giraud \& Lucas, 2009), that provides limited career prospects to mothers, within the academy and elsewhere. This specific societal context implies contrasting expectations and experiences for the male and female postdocs we interviewed.

Firstly, Switzerland is perceived as a potentially attractive destination for dual-postdoc couples, simply because of the sheer numbers of postdoc positions available in the country, combined with the excellent Swiss transport infrastructure and reputation as a safe and prosperous destination (Ravasi et al., 2015). It is thus relatively easy for couples to envisage a 'joint' move to Switzerland, on the condition that the partners' employability is 'portable' or that the partner is willing to suspend his/her own career prospects. In the past, this requirement usually gave male postdocs an advantage, because they were statistically more likely to be accompanied by a so-called 'trailing wife' (Bruegel, 1996), who could and would put her career aspirations on hold, at least for the duration of the 'probationary' postdoc phase. This is no longer the case. Male and female postdocs are now likely to be involved in complex 'dual career' configurations, potentially involving extended periods of livingapart-together (LAT) arrangements, and ultimately resulting in (fragile) long-distance relationships, stalled parenthood and emotional instability (Sautier, 2020). For example, Helena, a Spanish citizen, initially accepted a postdoc position in Switzerland on the understanding that her male partner, whom she had met while they were both PhDs, would come with her and look for a (non-academic) job. In reality, the Swiss labour market was not as open as expected and he also had problems with the immigration authorities. Although the partner did eventually receive a job offer in Switzerland, he had already decided to go back to Spain. Their relationship ended at that point, because Helena refused the 'long-distance' LAT model that was prevalent among her postdoc colleagues.

So, even when couples are able to make a joint move to Switzerland, adopting a 'dual career' lifestyle often turns out to be complicated. Also, they frequently end up adopting more traditional gender arrangements than initially intended (Elcheroth et al., 2011). The Swiss gender regime has been described as 'neo-maternalistic' (Giraud \& Lucas, 2009), since it rests on a 'modified male-breadwinner' configuration, with most women leaving the labour market entirely, or significantly reducing their working time after the birth of a child (OFS, 2018). The female postdocs who have children in Switzerland are thus faced with a number of additional challenges. On the one hand, they must find practical and affordable solutions to the family childcare needs, on a limited budget, and with an unpredictable work schedule. On the other hand, they must convince their PI of their 'deservingness', despite the supposed 'incompatibility' of the aspiration for an academic career with their roles as mother and carer. This conception of motherhood as something that is fundamentally incompatible with the 'unencumbered commitment' to academic excellence was frequently expressed, both by male and female PIs, in the course of our fieldwork (Herschberg et al., 2016; Fassa et al., 2019). Sometimes our interviewees also saw motherhood as a concrete hindrance to women's careers. More often, they expressed the idea that this was how motherhood was perceived in the Swiss context, making it difficult to overcome what were deeply engrained beliefs. These were evident in the fact that most of the male PIs were in 'modified malebreadwinner' households, where their female partners had significantly reduced their working hours (and career ambitions) once their children were born. The (few) female PIs were more likely to be single and/or childless, particularly in the older generations, where the 'queen bee' attitude to younger (particularly 
female) colleagues who supposedly 'want to have it all' is particularly prevalent (Faniko et al., 2016).

Of course, there are exceptions to this rule, but they require a particular configuration of the intimate arrangements of the early-career stage academics and of their working environment. Some of our interviewees demonstrate the importance of joint commitment to a dual career life-style by couples throughout the 'probationary citizenship' period (see Mancini-Vonlanthen et al., 2019). Thus, when we interviewed Julia, a 35-year-old Italian-born plant biologist, married with two young children (both under 5 ), she had recently been recruited to a tenure-track junior group leader position at a German university. As with most of our STEM postdocs, Julia had had a very internationally mobile career, having done her Master in Italy, her $\mathrm{PhD}$ in Austria, and four years of postdoc in Switzerland. As often among female researchers (Bataille, 2016), Julia's (male) partner was also an aspiring academic. Confirming previous research findings (Schaer, et al., 2017), Julia emphasizes how this dual career couple configuration is often detrimental to the female partner, especially if the transition to parenthood takes place before she achieves tenure : 'if someone gives up, it's most likely the woman'. However, Julia and her partner agreed during the PhD to favour the career of the 'first to get offered a decent position'. When Julia was offered a postdoc in Switzerland, her husband joined her there a year later, having secured a Marie Curie Fellowship in the meantime. When she was then recruited to a tenure-track position after they had their first child, he followed her to Germany and finally abandoned his own academic career ambitions, to work in industry.

\section{The Gendering of 'Probationary Academic Citizenship'}

As we have shown in the previous section, we found evidence of subtle gender differences in the transition into and out of this 'probationary citizenship' phase. To begin with, there are signs that women are considered to be potentially more reliable 'team players' by future PIs, and that this may actually give them a competitive edge over their male counterparts at the highly competitive point of recruitment to a postdoc position in the Swiss context. This stereotypical image of women as being more suited to a subordinate position of 'research collaborator' to a senior (usually male) PI, could explain the particular pattern of the 'leaky pipeline' in the Swiss context, where women make up over $60 \%$ of $\mathrm{PhDs}$, but only $23 \%$ of professors, and where their relative numbers start to decline precisely during the postdoc phase of the 'survivor' career path (Dubach et al., $2017: 89$ ).

When they arrive in Switzerland to take up a postdoc position, these highly qualified men and women are equally committed to an academic career, and they share similar perceptions of what this entails. They know that they are expected to demonstrate 'unlimited commitment' to the scientific endeavour, putting in long hours and adapting to unpredictable schedules, to be 'highly productive' in this limited time-span, and to accept 'unfettered' mobility requirements, implying the need to 'suspend' the consolidation of their intimate relationships and delay any aspirations for parenthood, especially if childcare can't be allocated to a 'trailing spouse' of either sex. The postdocs tend to accept the legitimacy of these expectations, on which the continued patronage of their PIs depends, whilst also recognising that such demonstrations of 'deservingness' ultimately offer no guarantee of progression to a tenured position, particularly not in the same institution, or even the same country.

The feminine advantage at the point of recruitment is not maintained during the transition out of the 'probationary citizenship' phase and it is clearly around the divergent prescriptions the postdocs face as 'reliable subordinate collaborators' or as potential 'intellectual entrepreneurs' and 'team leaders' that gender segregation mechanisms come into play.

First, women are more likely than their male counterparts to undertake daily housekeeping and childcare duties alongside their heavy academic workload and they are less likely than their male colleagues to receive support from their spouse of other family members in this regard (Bataille et al., 2017; see also Chapter 5 in the present volume). Unsurprisingly, as we have seen, female postdocs receive more negative evaluations of their 'deservingness' of continued patronage around the transition to parenthood. Nevertheless, this is not only associated with an objectively negative effect of motherhood on their personal academic record (notably scientific publications). It is also a result of the 'risk' a pregnant woman or mother of a young child is perceived to represent, in the Swiss context, for the timely completion of the research undertakings of the PI who recruited her and to whom she is ultimately answerable. The pregnant postdoc, along with any father who requests time out to dedicate to his family, is suspected of less than total commitment to the academic career, but, more importantly, of failing to adequately repay the symbolic 'debt' owed to 
the PI for having 'invested' in that particular person, among a myriad of other, equally 'deserving', hopeful candidates. Because the Swiss academic market is so attractive, because the socioeconomic environment is so unsupportive to working parents, but also because women continue to bear the 'mental burden' of synchronizing schedules within the household, they are likely to be judged more harshly (i.e. as 'less deserving') than their male counterparts, particularly in a country with shared beliefs and institutional arrangements predicated on the fundamental 'incompatibility' of motherhood and a demanding career.

Secondly, women appear to be particularly suited to the intellectual and organizational subordination that is required of postdocs in the Swiss context. Throughout our fieldwork, we observed that men experienced a more straightforward and rapid transition out of the 'probationary citizenship' phase than women, either because they are more easily recognised as 'deserving' of full academic citizenship (Fassa \& Kradolfer, 2010), or because they have more opportunities for opting out of the academic 'citizenship game' altogether, without compromising their future career prospects. Women, on the other hand, appear to be particularly vulnerable to extended periods of 'probationary citizenship' and, after several successive highly 'successful' postdoc positions, they are more likely to be offered various forms of 'subordinate inclusion' in the academy, via pseudoacademic jobs that offer only 'limited' or 'second class' citizenship status.

The less favourable outcomes of the 'probationary postdoc' phase for women result from a combination of factors. For reasons that are partly related to the negative perception of their family and domestic commitments, partly related to the moral reprobation associated with women appearing to be 'too ambitious' (Faniko et al., 2016), and partly related to the less favourable employment opportunities available to them outside of the academy, female postdocs and their mentors seem to envisage a 'durably subordinate' membership of the academic community as an acceptable career outcome for a woman, particularly if she appears to be 'encumbered' by family engagements or geographically 'fettered' in any way. Since women are acutely aware that motherhood tends to position them as 'less deserving' of continued patronage, irrespective of their practical childcare arrangements and objective work commitments, they are more likely to see the decision to have children as a barrier to full academic citizenship, and to scale down their ambitions accordingly.

It would thus seem that male postdocs tend to adhere to the 'up or out' principle of the survivor career model, particularly if they have family responsibilities and aspire to a traditional 'male (main) breadwinner' role (Bataille et al., 2016). Female postdocs, in contrast, not only receive less support from their PIs and partners to 'move up' the academic career ladder, they also face labour market discrimination and have fewer alternative career opportunities (Studer, 2012). They are therefore less likely to 'exit' the academic citizenship path strategically, in the search for more promising career opportunities elsewhere (cf. Glass et al., 2013), and more likely to 'hold on' to any form of academic employment, until all prospects of tenure have finally evaporated and until there are no more administrative avenues to a 'permadoc' status available.

We would thus argue that persistent gender inequalities in the Swiss academic labour market result not only from the 'exclusion' of women through discriminatory selection mechanisms, but also from their prolonged 'subordinate inclusion' (Chauvin \& Garcés-Mascarenas, 2015) in the academic community, via a secondary (Piore \& Sable, 1984) internal academic labour market.

\section{Conclusion}

Developing the notion of 'probationary citizenship' has been particularly useful in identifying one of the core aspects of the postdoc experience that has been relatively undocumented to date, namely the 'divergent prescriptions' male and female postdocs face at different stages of a typical (Swiss) 'survivor' academic career path. We have thus shown that the successful completion of the postdoc 'probationary citizenship' phase requires demonstrating various forms of subordination to the scientific leadership of a (usually male) senior academic, on whose patronage continuing academic employability depends. However, at the end of the postdoc period, the transition to full academic citizenship requires the very same postdocs to demonstrate the intellectual 'leadership' qualities that are a prerequisite for recruitment to a tenured professorship; qualities that are by no means fostered or valued during the 'probationary' career stage, particularly in women (Faniko, et al., 2016).

More generally, our research suggests that the Swiss postdoc phase tends to encourage and reward fairly conservative gender arrangements. The men who succeed the transition to full academic citizenship usually benefit from the informal support of a 'flexible' spouse, whose own career prospects are tailored to the needs of the internationally mobile male career path. Although we did uncover some cases of 'gender 
subversion' in dual career couples (Le Feuvre, 2009), women usually face the additional challenge of being taken seriously, not only as 'excellent' researchers and teachers, but also as academic authority figures, with outstanding management potential.

Our fieldwork suggests that couples who aspire to more egalitarian life-style arrangements are unlikely to 'survive' the lengthy 'probationary' postdoc phase. Men who want to invest in their home life and to support the career advancements of their partner are most likely to abandon their aspirations for an academic career and to prefer alternative employment options (Bataille, et al., 2016). Women who can count on the active support of a spouse, not only for the daily management of the household, but also for the bolstering of their self-confidence and claims to become independent academics in their own right, are likely to favour a destination country and academic environment that is more conducive than Switzerland to dual-career practices across the life-course.

It is important to stress here that the unfavourable outcome of the 'probationary postdoc' phase for female postdocs is not directly related to the 'hampering' of their academic potential after the transition to motherhood. Overall, 'scientific productivity' is relatively independent of gender, partnership or parental status (Yang \& Weber, 2015). It is thus something of a sociological fallacy to believe that motherhood per se reduces the ability of women to compete on an equal footing with men on a range of objective indicators of 'academic excellence', however this is defined and measured (O'Connor \& O'Keefe, 2017). On the contrary, what counts is the significance collectively attached to motherhood, and to other care commitments, as an indicator of women's less than total 'deservingness' of full academic citizenship, and thus their access to recognition, patronage and, ultimately, a tenured professorial position.

As we have seen, the negative influence of such beliefs can be reduced under at least two - largely ideological - conditions. Firstly, it is necessary that care commitments, including motherhood, cease to be associated with a lack of 'deservingness' of further patronage by individual PIs and with a lack of recognition and reward by members of the academic community as a whole. Secondly, a firm commitment within postdoc households (and extended families) to the equal value of male and female career aspirations and the adoption of practical, daily arrangements that are conducive to 'dual career' households (ManciniVolanthen et al., 2019).
The main problem for female postdocs in the Swiss context is not 'exclusion' from the academic community, but rather something akin to 'membership without citizenship' (Brubaker, 1989 : 145). Unfortunately, the sheer size of the Swiss 'postdoc bubble' presents a serious challenge to the development of a sustainable 'gender equality culture', despite rhetorical, financial and organizational commitment to this policy agenda over the past 20 years.

\section{Notes}

1. The resulting categories are defined as follows : Professors (Profs), including Full, Associate and Assistant professorial positions with tenure or on tenure-track; Other academic staff (Oth. teach), including non-professorial academic positions, such as Lecturer or Senior Lecturer, some of which are stable, and which require a $\mathrm{PhD}$; Teaching and/or research positions (Postdocs), fixed-term, reserved for people with a $\mathrm{PhD}$; Teaching and/or research positions (AssDoc), fixed-term, reserved for people without a $\mathrm{PhD}$ (e.g. Graduate Students) Administrative and technical support staff, (Admin. and Tech. Staff), stable or fixed-term, sometimes requiring a $\mathrm{PhD}$.

2. This category includes $\mathrm{PhD}$ candidates with Swiss nationality and foreigners who received their Maturité (school leaving certificate) from a Swiss secondary school.

3. Names and certain biographical details have been modified to protect the identity of the interviewees.

4. There is no legal paternity leave in Switzerland (Lanfranconi \& Valarino, 2014).

5. This measure was implemented in 2018.

6. This only applies to staff on the payroll of a university, and not to those working on externally funded projects.

7. A six-month 'job search' extension permit can be requested by non-EU citizens who complete a funded $\mathrm{PhD}$ contract in Switzerland, but no equivalent arrangement exists for most foreign postdocs. 


\section{References}

Afonso, A. (2016). Varieties of Academic Labour Markets in Europe, Political Science 85 Politics, 49(4), 816-824. Doi:10.1017/S1049096516001505

Bataille, P. (2016). "Qualitative report on the leaky pipeline in Switzerland", in B. Fusulier \& F. Dubois-Shaik (Eds.), GARCIA Report D6.2. Trento : University of Trento, 190-221.

Bataille, P. (2017). "Quand le genre rattrape l'excellence. Une comparaison des parcours de formation et d'insertion des normaliens et normaliennes (19811987)", In H. Buisson-Fenet (Ed.) École des filles, école des femmes. L'institution scolaire face aux parcours, normes et rôles professionnels sexués, Bruxelles : de Boeck supérieur, 73-88.

Bataille, P., Le Feuvre, N., Kradolfer, S. (2017). "Should I Stay or Should I Go? The effects of precariousness on the gendered career aspirations of postdocs in Switzerland", European Educational Research Journal, Special Issue Work-Life Interferences in Scientific Careers, 16(2-3), 313-331.

Bataille, P., \& Sautier, M. (2019). "Ce que 'être postdoc' veut dire. Cheminements postdoctoraux en Suisse circa 2010", Philosophia Scientiae, 23(3), 3-34.

Beaufaÿs, S., \& Krais, B. (2005). Femmes dans les carrières scientifiques en Allemagne : les mécanismes cachés du pouvoir. Travail, genre et sociétés, 14, 4968.

Brubaker, R. (1989). "Membership without citizenship. The Economic and Social Rights of Noncitizens", In R. Brubaker (Ed.) Immigration and the Politics of Citizenship in Europe and North-America, Lanham : University Press of America, 145-162.

Bruegel, I. (1996). "The Trailing Wife : A Declining Breed". In R. Crompton, G. Duncan, \& K. Purcell (Eds.), Changing Forms of Employment. Organizations, Skills, and Gender. London : Routledge, 235258.

Chauvin. S. \& Garcés-Mascarenas, B. (2012). "Beyond Informal Citizenship. The New Mixed Economy of Migrant Illegality", International Political Sociology, 6, 241-259.

Conesa Carpintero, E. \& González Ramos, A.-M. (2018). "Accelerated Researchers : Psychosocial Risks in Gendered Institutions in Academia", Frontiers in Psychology 9(1077), 1-13. doi:10.3389/fpsyg. 2018. 01077 del Río Carral, M., \& Fusulier, B. (2013). Jeunes chercheurs face aux exigences de disponibilité temporelle. Quelles logiques d'agencement entre la vie professionnelle et la vie privée? Temporalités (18), Accessed July $10^{\text {th }} 2019$ : https://doi.org/10.4000/temporalites.2614

Dubach, P. (2015). La relève scientifique dans les universités suisses : indicateurs statistiques concernant les conditions de travail et les perspectives de carrière, Report to the Secrétariat d'Etat ä la formation, la recherche et l'innovation (SEFRI), Bern : Buro BASS.

Dubach, P. (2011). La relève scientifique dans les universités suisses : indicateurs statistiques concernant les conditions de travail et les perspectives de carrière. Report to the Secrétariat d'Etat ä la formation, la recherche et l'innovation (SEFRI), Bern : Buro BASS.

Dubach, P., Legler, V., Morger, M., Stutz, H. (2017). Femmes et hommes dans les hautes écoles suisses. Indicateurs de l'égalité des chances aux études et dans la carrière scientifique, Report to the Secrétariat d'Etat ä la formation, la recherche et l'innovation (SEFRI), Bern : Buro BASS.

Dubois-Shaik, F., Fusulier, B., \& Vincke, C. (2018). A gendered pipeline typology in academia. In A. Murgia \& B. Poggio (Eds), The Precarisation of Research Careers : A Comparative Gender Analysis. London : Routledge, 178-205.

Elcheroth, G., Bühlmann, F., \& Tettamanti, M. (2011). Valeurs égalitaires et pratiques sexuées : une approche biographique et comparative, In D. Joye, C. Pirinoli, D. Spini, \& E. Widmer (Eds.) Parcours de vie et insertions sociales. Zurich : Seismo, 81-104.

Enders, J., \& Musselin, C. (2008). Back to the future? The academic professions in the 21st century, In OECD (Ed.) Higher Education in 2030. Volume 1 : Demography, Paris : OECD, 125-150.

Faniko, K., Ellemers, N., \& Derks, B. (2016). Queen Bees and Alpha Males : Are successful women more competitive than successful men? European Journal of Social Psychology, 46(7), 903913. https://doi.org/10.1002/ejsp.2198

Fassa, F., Benninghoff, M., Kradolfer, S., (coord.) (2019). Universités : Les politiques d'égalité entre les femmes et les hommes ä l'heure de l'excellence, Special issue on-line journal SociologieS. http: // journals. openedition. org/sociologies/11773

Fassa, F., del Río Carral, M., \& Bataille, P. (2016). Organizational practices in Switzerland, In S. Cukut Krili?, T. Petrovi?, D. Kne?evi? Ho?evar, \& M. ?erni? Isteni? (Eds.), GARCIA Report D4.4. Trento : University of Trento, 168-199.

Fassa, F., \& Kradolfer, S. (2013). "The Gendering of Excellence Through Quality Criteria : The case of 
the Swiss National Science Foundation Professorships in Switzerland". Tertiary Education and Management, 19(3), 189-204.

Fire, M., \& Guestrin, C. (2019). Over-optimization of academic publishing metrics : observing Goodhart's Law in action, GigaScience, 8, 1-20. doi : 10.1093/gigascience/giz053

Giraud, O. and Lucas, B. (2009). Le renouveau des régimes de genre en Allemagne et en Suisse : Bonjour 'néo-maternalisme'?, Cahiers du genre, 1(46), 17-46.

Glass, J. L., Sassler, S., Levitte, Y., and Michelmore, K. M. (2013). What's so special about STEM? A comparison of women's retention in STEM and professional occupations. Social Forces, 92(2), 723756.

Heijstra, T. M., Steinthorsdóttir, F. S., and Einarsdóttir, T. (2017). Academic career making and the double-edged role of academic housework. Gender \& Education, 29(6), 764-780. doi : 10.1080/09540253.2016.1171825

Herschberg, C., Benschop, Y., \& Van den Brink, M. (Eds.). (2016). Gender Practices in the Construction of Excellence, GARCIA working paper $\mathrm{n}^{\circ} 10$. Trento : University of Trento.

Lanfranconi, L. M., \& Valarino, I. (2014). Gender equality and parental leave policies in Switzerland : A discursive and feminist perspective. Critical Social Policy, 34(4), 538-560. https://doi.org/10.1177/0261018314536132

Le Feuvre, N. (2016). Contextualizing Women's Academic Careers in Cross-National Perspective. GARCIA Working Paper $\mathrm{n}^{\circ} 3$, Trento : University of Trento.

Le Feuvre, N. (2009). "Exploring Women's Academic Careers in Cross-National Perspective : Lessons for Equal Opportunity Policies", Equal Opportunities International, 28(1), 9-23 doi.10.1108/02610150910933604

Le Feuvre, N., Bataille, P., Kradolfer, S., del Rio Carral, M., Sautier, M. (2018). The Gendered Diversification of Academic Career Paths in Comparative Perspective, In A. Murgia and B. Poggio (Eds.) Gender and Precarious Research Careers : A Comparative Analysis, London : Routledge Research in Gender \& Society Series, 50-80.

Mancini-Vonlanthen, Le Feuvre, N., Davoine, E. (2019). Couple-based self-initiated expatriation : An opportunity or hazard for highly-qualified women? Paper presented to the LIVES IP6 Seminar, Lausanne : Lausanne University, May $28^{\text {th }}$.

Moreau, M.-P., \& Robertson, M. (2019). 'You scratch my back and I'll scratch yours'? Support to academics who are carers in Higher Education, Social Science, 8(164), 1-12. doi:10.3390/socsci8060164

Müller, R. (2014). Racing for What? Anticipation and acceleration in the work and career practices of academic life science postdocs. Forum Qualitative Social Research 15(3). http://nbnresolving.de/urn:nbn:de:0114-fqs1403150

Müller, R. (2014). Postdoctoral life scientists and supervision work in the contemporary university : A case study of changes in the cultural norms of science. Minerva, 52(3), 329-349.

Nokkala, T., Bataille, P., Siekkinen, T., \& Goastellec, G. (2020). Academic career, international mobility and the national gender regimes : comparison of Swiss and Finnish polities. In T. Nokkala \& L. Weimer (Eds.) Universities as political institutions HEIs in the middle of academic, economic, and social pressures, Leiden : Brill (forthcoming).

Office Fédérale de la Statistique (OFS). (2018). Personnel des hautes écoles universitaires en 2017, Neuchâtel : Swiss Federal Statistical Office.

Office Fédérale de la Statistique (OFS). (2018). Comments on findings for the period 2012-2018. Labour market indicators for 2018. Neuchâtel : Swiss Federal Statistical Office.

O'Connor, P. \& O'Hagan, C. (2016). Excellence in university academic staff evaluation : a problematic reality? Studies in Higher Education 41 (11) 19431957.

O'Keefe, T \& Courtois, A. (2019). 'Not one of the family $^{6}$ : Gender and precarious work in the neoliberal university, Gender, Work \& Organization, doi:10. 1111 /gwao. 12346

O'Neill, M. (2014). The Slow University : Work, Time and Well-Being, Forum : Qualitative Social Research, 15(3), Available at : http://nbnresolving.de/urn:nbn:de:0114-fqs1403146.

Pain, E. (2014). An emerging global picture of early-career scientists. Science Careers, January, 27. Available at : https://www.sciencemag.org/careers/2014/01/emergingglobal-picture-early-career-scientists.

Piore, M. J. et Sabel, C. F. (1984). The second industrial divide : possibilities for prosperity. New York : Basic Books

Powell, K. (2015). "The future of the Postdoc, Nature, $\mathrm{n}^{\circ}$ 520, April $9^{\text {th }}$, pp. 14-147.

Ravasi, C., Salamin, X., \& Davoine, E. (2015). Cross-cultural adjustment of skilled migrants in a multicultural and multilingual environment : An explorative study of foreign employees and their spouses in the Swiss context. The International Journal of 
Human Resource Management, 26(10), 1335-1359. https://doi.org/10.1080/09585192.2014.985328

Reskin, B.F. \& Roos, P.A. (1990). Job Queues, Gender Queues : Explaining Women's Inroads into Male Occupations. Philadelphia : Temple University Press.

Roseneil, S., Crowhurst, I., Hellesund, T., Santos, A. C., \& Stoilova, M. (2012). Remaking Intimate Citizenship in Multicultural Europe : Experiences Outside the Conventional Family. In B. Halsaa, S. Roseneil, \& S. Sümer (Eds.), Remaking Citizenship in Multicultural Europe : Women's Movements, Gender and Diversity (pp. 41-69). https://doi.org/10.1057/9781137272157_3

Sassen, Saskia. (2002) Towards Post-National and Denationalized Citizenship. In E. Isin, and B. S. Turner (Eds.) Handbook of Citizenship Studies, London : Sage : 277-291.

Sautier, M. (2017). Chercheur.e.s sans frontières? La mobilité géographique des universitaires entre normes de carrière, idéal scientifique et pérégrinations intimes. MA dissertation, Lausanne : University de Lausanne.

Sautier, M., (2020). Move or Perish? The Transnational Mobility of Researchers in Swiss Academia. Higher Education. Special Issue 'Stuck and sticky in mobile academia : reconfiguring the im/mobility binary' (in press).

Schaer, M., Dahinden, J., Toader, Aline (2017). "Transnational mobility among early-career academics : Gendered aspects of negotiations and arrangements within heterosexual couples", Journal of Ethnic and Migration Studies. doi : 10.1080/1369183X . 2017. 1300254.

Seminario, R., Le Feuvre, N. (2017). "Snakes and Ladders : The Combined Effect of Education and Marriage on the Employment Trajectories of Peruvian Migrants in Switzerland", LIVES Working Paper 2017/63, doi : 10.12682/lives.2296-1658.2017.63

Shinonazi, K. (2017). "Gender and Citizenship in Academic Career Progression : An Intersectional, Meso-scale Analysis in German Higher Education Institutions, Journal of Ethnic and Migration Studies, 43(8) : 1325-46.

Steinthorsdóttir, F., Brorsen Smidt, T., Petursdottir, G. M., Einarsdóttir, T., Le Feuvre, N. (2019). "New Managerialism in the Academy : Gender Bias and Precarity", Gender, Work \& Organization, 26 : 124139. http://dx.doi.org/10.1111/gwao.12286

Sigl, L. (2012). Embodied anxiety. On experiences of living and coping with (conditions of) precarity in research cultures of the academic life sciences, $\mathrm{PhD}$
Thesis, Department of Science and Technology Studies, Vienna : University of Vienna, Austria.

Van den Brink, M., \& Benschop, Y. (2012). "Gender practices in the construction of academic excellence : Sheep with five legs". Organization, 19 (4), 507-524.

Van den Brink, M. and Benschop, Y. (2014) Gender in academic networking : The role of gatekeepers in professorial recruitment. Journal of Management Studies, 51 (3) : 460-492.

Vostal, F. (2015). "Academic life in the fast lane : The experience of time and speed in British academia". Time 6 Society, $24(1), 71-95$.

Ward, K. and Wolf-Wendel, L. (2004). Academic Motherhood : Managing Complex Roles in Research Universities, The Review of Higher Education, 27(2), 233-257.

Warren, J. R. (2019) "How much do you have to publish to get a job in a top sociology department? Or to get tenure? Trends over a generation", Sociological Science, 6 : 172-196.

Welsh, J. (2019). Dispossessing academics : The shift to 'appropriation' in the governing of academic life, European Journal of Social Theory, DOI : 10.1177/1368431019854998, 1-20.

Wolfinger, N. H., Mason, M. A., \& Goulden, M. (2008). "Problems in the pipeline : Gender, marriage, and fertility in the ivory tower". The Journal of Higher Education, 79(4), 388-405.

Yang, L., and Webber, K. L. (2015). A decade beyond the doctorate : the influence of a US postdoctoral appointment on faculty career, productivity, and salary. Higher Education, 70(4), 667-687.

Ylijoki, O.-H. (2003). Entangled in academic capitalism? A case-study on changing ideals and practices of university research. Higher Education, $45(3), 307-335$.

Ylijoki, O. H., \& Mäntylä, H. (2003). "Conflicting time perspectives in academic work". Time $\&$ Society, 12(1), $55-7$ 